\title{
Significance of Discontinuous Precipitation of Copper in Ancient Silver
}

\author{
R. J. H. Wanhill
}

Received: 9 September 2012/Revised: 5 October 2012/ Accepted: 5 October 2012/Published online: 27 November 2012 (C) Springer Science+Business Media New York and ASM International 2012

\begin{abstract}
Discontinuous precipitation of copper has been held responsible for much of the embrittlement of ancient silver objects. The detailed characteristics of this precipitation have been suggested as possible indicators of an object's age and authenticity. These proposals are considered in the light of metallographic and analytical studies of several embrittled artifacts. These studies indicate that discontinuous precipitation is much less significant for embrittlement than residual stresses due to retained cold-work and externally applied stresses due to burial, and that the precipitation characteristics cannot be used for authentication.
\end{abstract}

Keywords Ancient silver - Silver-copper alloys · Embrittlement

\section{Introduction}

Discontinuous precipitation of copper has been thought responsible for corrosion-induced and microstructurally induced embrittlement of ancient silver [1,2]. The eminent metallurgist C. S. Smith also stated that "silver alloys of any antiquity containing over about three percent copper are invariably brittle" [1]. By this, he apparently meantthe text is not entirely clear-that the brittleness was due mainly to corrosion along grain boundaries where discontinuous precipitation had occurred.

The idea that copper precipitation could result in microstructurally induced embrittlement was proposed by Werner [2]. This was taken up by Schweizer and Meyers

R. J. H. Wanhill ( $\square)$

National Aerospace Laboratory NLR, P.O. Box 153,

8300 AD Emmeloord, The Netherlands

e-mail:Wanhill@nlr.nl; Russell.Wanhill@nlr.nl
[3], who suggested also that the widths and detailed morphology of discontinuous precipitation might enable verification of the age, and hence authenticity, of silver artifacts $[4,5]$.

This article considers discontinuous precipitation of copper in the light of the foregoing assertions and suggestions. Use is made of seven case studies of embrittled ancient silver artifacts. Four of these studies were done at the NLR. The remaining three were done elsewhere.

\section{Discontinuous Precipitation of Copper in Silver}

\section{Basic Characteristics of Discontinuous Precipitation} (General Information)

Discontinuous precipitation is growth of a two-phase product behind a moving grain boundary that relieves a supersaturated $\alpha$ matrix, the reaction being $\alpha \rightarrow \alpha^{\prime}+\beta$, see Fig. 1. The adjective "discontinuous" refers to an abrupt change in matrix composition $\left(\alpha: \alpha^{\prime}\right)$ and not to the precipitate morphology.

The reaction begins with nucleation of $\beta$ at the grain boundary. As it moves, the grain boundary collects solute from the supersaturated $\alpha$ matrix, and the precipitate phase $\beta$ is then supplied with solute by grain-boundary diffusion, which is much faster than solute diffusion in the matrix. The result is that the $\beta$ precipitates can grow while remaining attached to the moving grain boundary. In turn, this often results in a lamellar microstructure behind the grain boundary, as indicated in Fig. 1, although this is not the case for copper in silver, as is discussed in the next section. Figure 1 also shows schematically, via colorshading, that the depleted matrix, $\alpha^{\prime}$, in the precipitation zone has changed its crystallographic orientation from 
grain 2 to that of grain 1 . This is an essential characteristic of discontinuous precipitation [6].

\section{Copper in Silver}

Discontinuous precipitation of copper in silver-copper alloys was first investigated by Fraenkel [7]. Many studies followed, e.g., Refs. [8-20]. All these studies involved

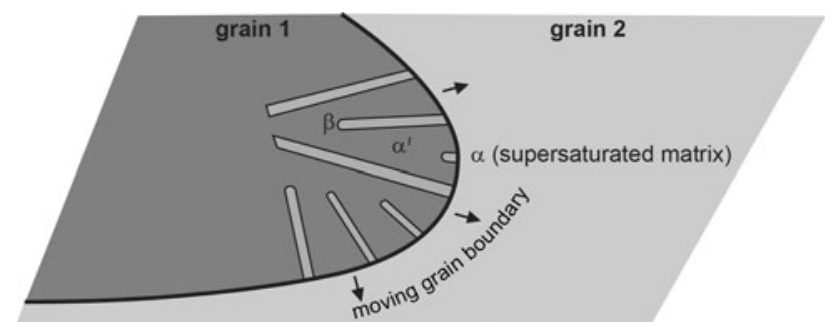

Fig. 1 Schematic of discontinuous precipitation, $\alpha \rightarrow \alpha^{\prime}+\beta$ precipitation experiments (aging) at elevated temperatures, usually above $200{ }^{\circ} \mathrm{C}$. Figure 2 illustrates the development of discontinuous precipitation in standard silver [8]. There are several noteworthy features, also visible in other studies $[1,3,5,11,13-17]$ :

(1) The precipitate colonies can be very variable in size, Fig. 2(b) and (c), and their appearance is mostly finely mottled, not lamellar. A lamellar microstructure often does not occur, especially at lower aging temperatures [13].

(2) Colonies can grow in opposite directions from adjacent or overlapping sites on the same original grain boundary. This occurs in other alloys too [21]. In view of the precipitation mechanism, this phenomenon is difficult to explain [22].

(3) Although the original grain boundaries are slightly curved or straight, the new grain boundaries formed

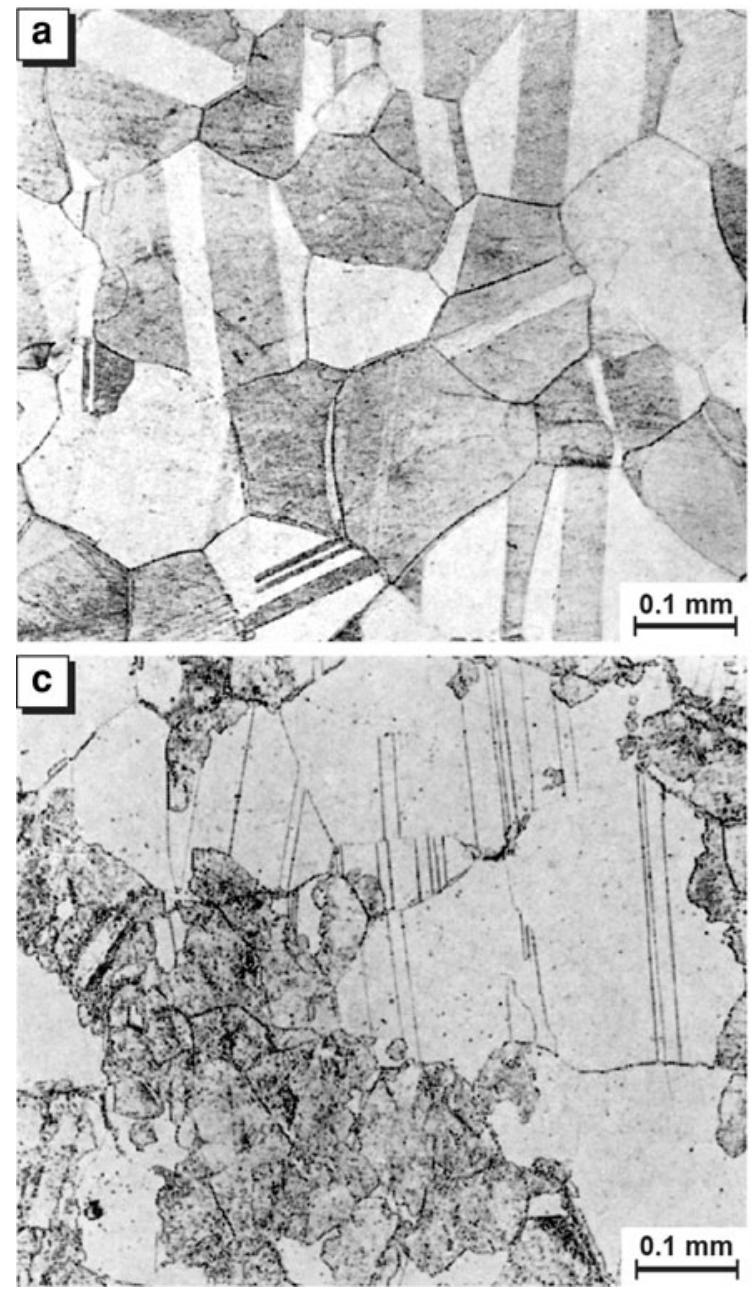

Fig. 2 Optical metallographs of discontinuous precipitation in $800{ }^{\circ} \mathrm{C}$ solutionized, quenched and $30 \mathrm{~min}$ aged standard silver, Ag-7.5 wt. $\% \mathrm{Cu}$ [8]. a $250{ }^{\circ} \mathrm{C}$ aged, precipitation starting at some grain boundaries. b $356{ }^{\circ} \mathrm{C}$ aged, precipitation further advanced.
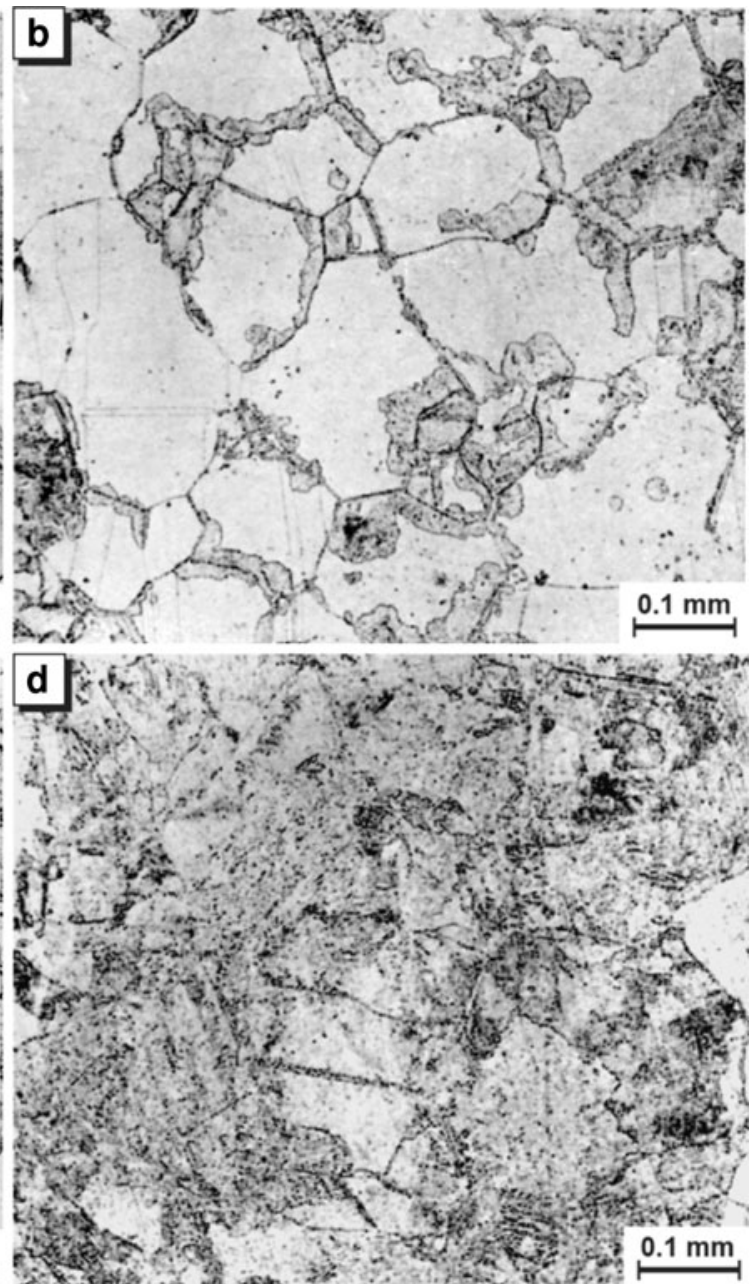

c $440{ }^{\circ} \mathrm{C}$ aged, precipitation still further advanced. d $570{ }^{\circ} \mathrm{C}$ aged, almost complete (micrographs reproduced courtesy of the Institute of Materials, London) 
by the moving reaction fronts are irregular. At low magnifications, this irregularity gives the new grain boundaries a meandering, wiggly appearance [1].

Figure 3 is a compilation of discontinuous precipitate growth rates versus aging temperatures for modern silvercopper alloys annealed before aging. The ordinate and abscissa scales assume Arrhenius reaction kinetics that enable straight-line extrapolations of the data to lower aging temperatures. These extrapolations suggest a maximum growth rate of $10^{-3} \mu \mathrm{m} /$ year at ambient temperatures. For artifacts 1000-2000 years old this means maximum precipitate widths of $1-2 \mu \mathrm{m}$. These would be visible from metallography, but there are two caveats. First, Fig. 3 shows that it is a long way from precipitation at $200{ }^{\circ} \mathrm{C}$ to possible precipitation at ambient temperatures. Besides uncertainty in the extrapolations, there is also no guarantee that Arrhenius reaction kinetics apply over the whole range. Second, elevated temperature tests have demonstrated incubation times before precipitation began [18]. At ambient temperatures, the incubation times could be very long: centuries or even millennia. Nevertheless, some ancient silver shows what is reasonably assumed [1,3-5] or proven [23, 24] to be discontinuous precipitation of copper, and it might have occurred mainly at ambient temperatures.

\section{The Case Studies}

Five of the ancient embrittled silver artifacts are portrayed in Figs. 4-8. The Gundestrup Cauldron, Egyptian Vase, and Roman Kantharos (drinking cup) are about 2000 years old. The Byzantine Paten (altar plate) and Romanesque Kaptorga (small container for relics and amulets) date, respectively, from the seventh and tenth centuries AD. The sixth case is a Sasanian King's Head dating from the fourth

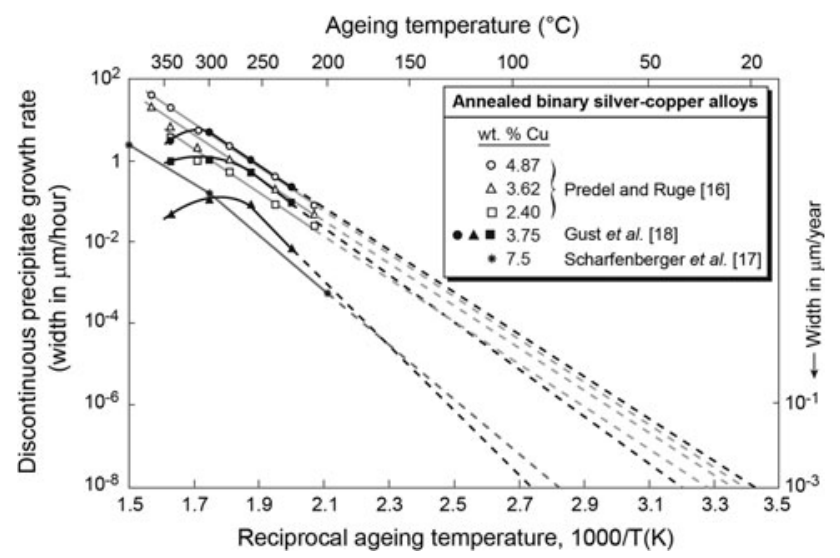

Fig. 3 Temperature dependence of discontinuous precipitation growth rates in binary silver-copper alloys. Extrapolations to low aging temperatures assume Arrhenius-type reaction kinetics century $\mathrm{AD}$ [25]; and the seventh is described only as a silver alloy sheet [1]. The artifacts vary in form and provenance. This variety is an advantage for assessing the overall significance of discontinuous precipitation of copper in ancient silver.

Table 1 lists the techniques, besides visual examination, used to examine small samples from the artifacts. Limitations were imposed by the available samples and techniques: Fractography could not be done on embedded metallographic samples from the Cauldron and Paten; chemical analyses other than energy-dispersive $\mathrm{x}$-ray spectroscopy (EDX) were not possible for the Vase and Kaptorga; electron backscatter diffraction (EBSD) was available only for the Cauldron; and Smith [1] and Lefferts

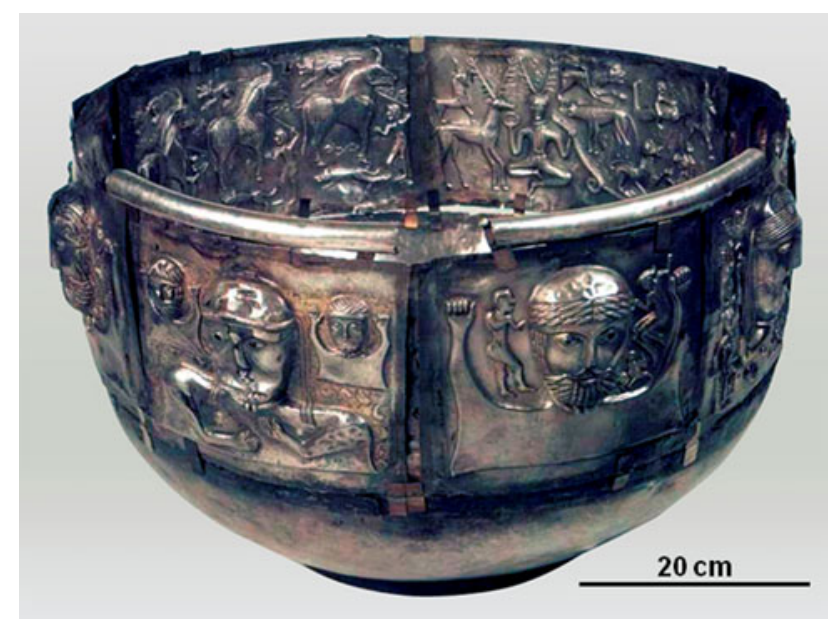

Fig. 4 Gundestrup Cauldron, National Museum of Denmark, Copenhagen

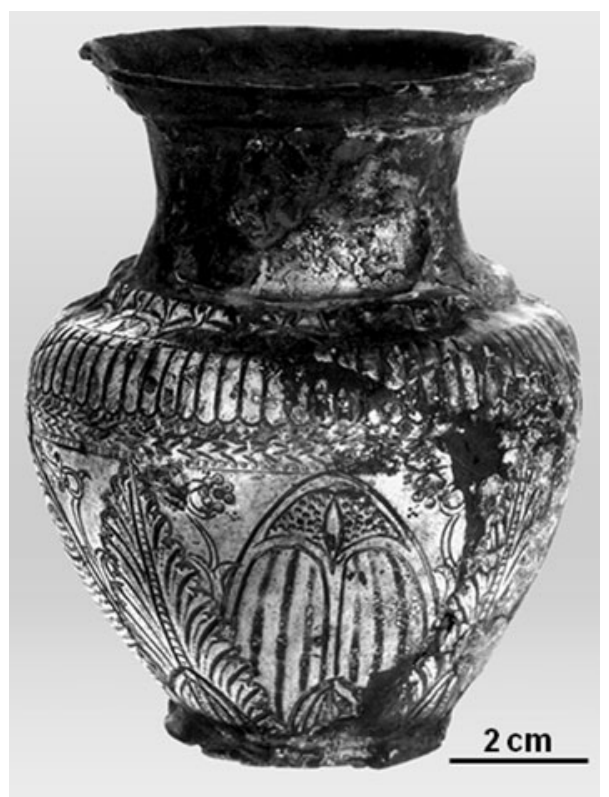

Fig. 5 Egyptian Vase, Allard Pierson Museum, Amsterdam 
[25] most probably did not have access to a scanning electron microscope (SEM). Also, only a sample from the Kantharos inner cup was available to the NLR, and although fractography was possible, the sample was too fragile to be prepared for metallographic examination.

Tables 2 and 3 survey the results, which have been described previously [1, 23-30], but not all together and not with the emphasis on discontinuous precipitation of copper. The results relevant to this theme will be considered in the following sections, but in the meantime it should be noted that the Vase and Cauldron case studies have demonstrated the primary importance of retained cold-work in causing and facilitating corrosion-induced embrittlement [23, 24, 26]. This is also likely for the Paten, which underwent large-scale breakage along annular indented grooves, see Fig. 6. Making these grooves would have introduced significant residual stresses [23], and the Paten was probably not subsequently annealed.

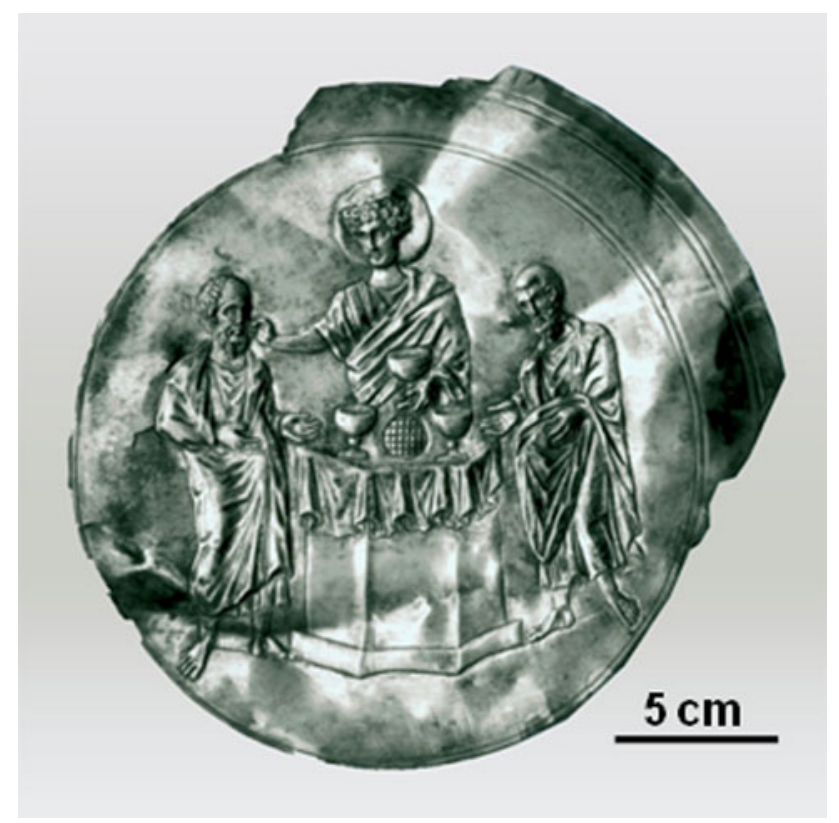

Fig. 6 Byzantine Paten, The Menil Collection, Houston
Discontinuous Precipitation of Copper and CorrosionInduced Embrittlement

Intergranular corrosion-induced embrittlement of ancient silver has been attributed, at least partly, to discontinuous precipitation $[1,2,31]$. However, Tables 2 and 3 show that discontinuous precipitation occurred in the corrosionembrittled Paten, Head, and Sheet, but not in the Vase and Kaptorga and the embrittled Cauldron samples. Furthermore, the one Cauldron sample that contained discontinuous precipitation was unembrittled. Thus, this type of precipitation is not necessary for intergranular corrosion-induced embrittlement (in the case of the Cauldron it was innocuous), but it may facilitate the embrittlement process [30]. This is discussed in the next main section of the article.

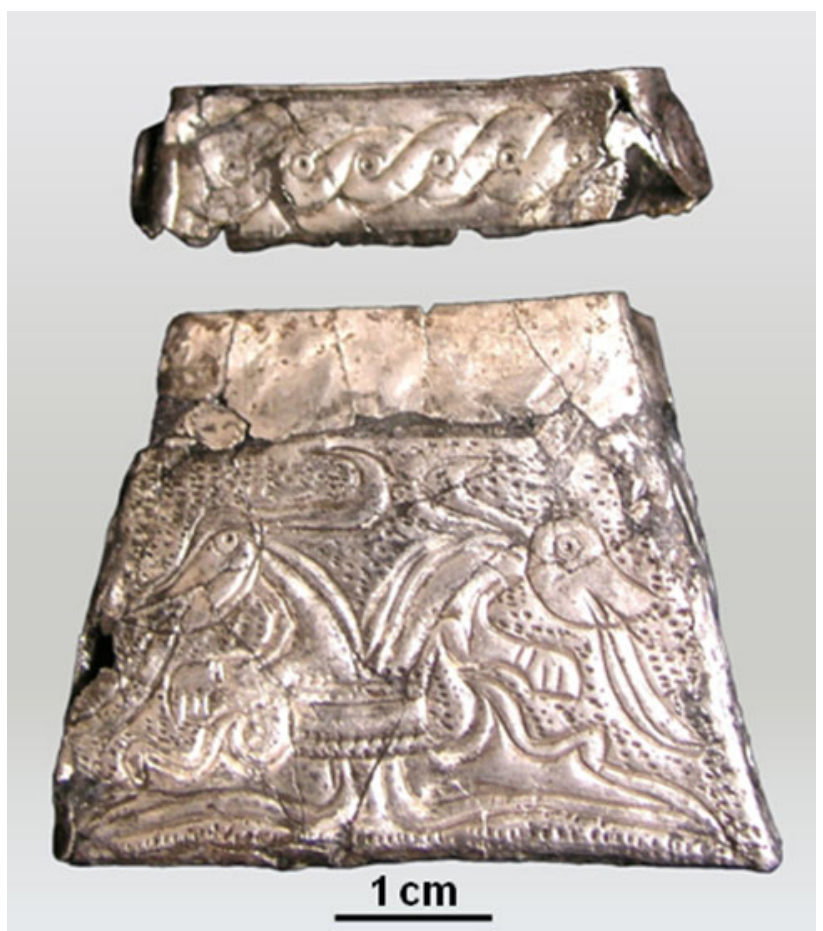

Fig. 7 Romanesque Kaptorga, Institute of Archaeology, Prague
Fig. 8 Roman Kantharos, Museum Het Valkhof, Nijmegen

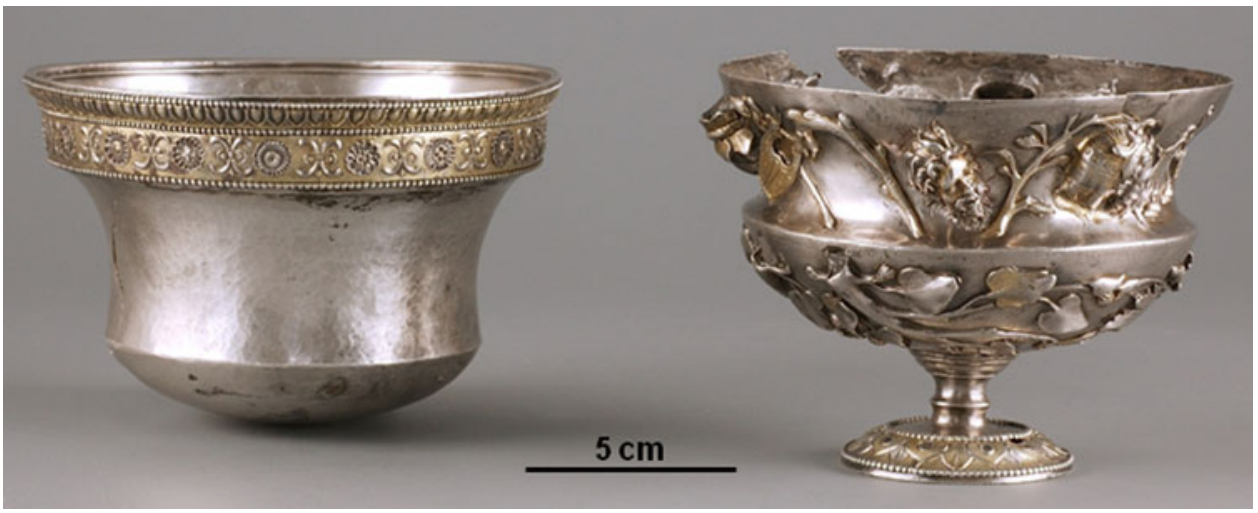


Table 1 Diagnostic techniques used to examine the ancient silver artifacts

\begin{tabular}{|c|c|c|c|c|c|c|c|}
\hline Techniques & Cauldron & Vase & Paten & Kantharos & Kaptorga & Head & Sheet \\
\hline $\mathrm{X}$-ray radiography & & $\bullet$ & & $\bullet$ & & & \\
\hline Optical metallography & & & & & $\bullet$ & $\bullet$ & 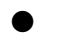 \\
\hline Vickers microhardness (HV) & & $\bullet$ & & & & $\bullet$ & \\
\hline SEM metallography & 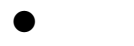 & $\bullet$ & $\bullet$ & & $\bullet$ & & \\
\hline EBSD & ○ & & & & & & \\
\hline SEM fractography & & $\bullet$ & & 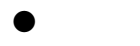 & $\bullet$ & & \\
\hline EDX chemical analysis & ○ & ○ & 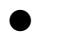 & & $\bullet$ & & \\
\hline Chemical analysis* & ○ & & - & ○ & & - & \\
\hline
\end{tabular}

* Electron probe microanalysis EPMA (Cauldron, Paten); x-ray fluorescence XRF (Kantharos); semi-quantitative spectrography (Head)

Table 2 Survey of the results for samples from the ancient silver artifacts

\begin{tabular}{|c|c|c|c|c|c|c|c|}
\hline Observations & Cauldron & Vase & Paten & Kantharos & Kaptorga & Head & Sheet \\
\hline \multicolumn{8}{|l|}{ Corrosion } \\
\hline Intergranular & 3 Samples & & $\bullet$ & & $\bullet$ & $\bullet$ & $\bullet$ \\
\hline Transgranular & 1 Sample & $\bullet$ & & & & & \\
\hline \multicolumn{8}{|l|}{ Microstructural embrittlement } \\
\hline Annealed microstructure & 1 Sample & & $\bullet$ & $\bullet$ & $\bullet$ & & $\bullet$ \\
\hline Retained cold-work & 3 Samples & $\bullet$ & & & & $\bullet$ & \\
\hline Discontinuous precipitation $\mathrm{Cu}$ & 1 Sample & & $\bullet$ & & & b.d. & $\bullet$ \\
\hline \multicolumn{8}{|l|}{ Composition* (wt.\%) } \\
\hline $\mathrm{Cu}$ & $1.76-4.64$ & 0.9 & 5.33 & $0.45-0.63$ & $3.3-3.5$ & $\sim 5$ & \\
\hline $\mathrm{Au}$ & $0.29-0.36$ & 0.8 & 0.58 & $0.58-0.63$ & $2.3-2.5$ & $0.1-1$ & \\
\hline $\mathrm{Pb}$ & $0.39-0.64$ & 0.7 & 0.86 & $0.16-0.25$ & n.d. & $0.05-0.5$ & \\
\hline $\mathrm{Bi}$ & $0.07-0.13$ & n.d. & 0.06 & n.d. & n.d. & $0.01-0.1$ & \\
\hline \multicolumn{8}{|l|}{ Corrosion product } \\
\hline $\mathrm{AgCl}$ & & 0 & & & 0 & 0 & \\
\hline
\end{tabular}

* Main elements, balance Ag

n.d., not detectable; b.d., barely detectable

Table 3 Gundestrup Cauldron samples and results

\begin{tabular}{|c|c|c|c|c|}
\hline Observations & 361 & 363 & 365 & 366 \\
\hline \multicolumn{5}{|l|}{ Corrosion embrittlement } \\
\hline Intergranular & 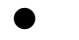 & $\boldsymbol{0}$ & $\bullet$ & \\
\hline Transgranular & & & $\bullet$ & \\
\hline Annealed microstructure & & & & 0 \\
\hline Retained cold-work* & $\bullet$ & $\bullet$ & $\bullet$ & \\
\hline Discontinuous precipitation of copper & & & & \\
\hline Copper content (wt.\%) & 4.64 & 1.76 & 2.17 & 3.44 \\
\hline
\end{tabular}

* Increasing retained cold-work in the order $361<363<365$

Discontinuous precipitation of copper at grain boundaries would not be expected to be relevant to transgranular corrosion-induced embrittlement of ancient silver. Tables 2 and 3 show that transgranular corrosion-induced embrittlement occurred in one Cauldron sample and the Vase, and in both cases discontinuous precipitation was absent.
Discontinuous Precipitation of Copper and Microstructurally Induced Embrittlement

There have been three suggestions for the cause of microstructurally induced embrittlement in ancient silver. These are lead precipitation at grain boundaries [32], atomic segregation of lead to grain boundaries [26], and discontinuous precipitation of copper along grain boundaries [1-3].

Table 2 shows that discontinuous precipitation of copper was not present in the microstructurally embrittled Vase and Kantharos samples. This negates the suggestion of microstructural embrittlement by copper, which is anyway untenable on modern empirical [8, 32] and theoretical [33] grounds. In fact, the best evidence against microstructural embrittlement by copper is provided by Norbury's mechanical property data [8]. Figure 9 shows these data: Although discontinuous precipitation of copper caused large changes in tensile strength and elongation, the minimum tensile elongation was about $34 \%$, which still indicates high ductility and certainly not embrittlement. 
The most likely perpetrator of microstructurally induced embrittlement is lead [23, 26, 29, 32, 33], particularly because of Thompson's and Chatterjee's [32] experiments, and also because the next likely perpetrator is bismuth [33], which was not detected by chemical analysis of samples from the Vase and Kantharos, see Table 2.

Discontinuous Precipitation, Copper Content, and Embrittlement

As mentioned in section 1, Smith stated that "silver alloys of any antiquity containing over about three percent copper

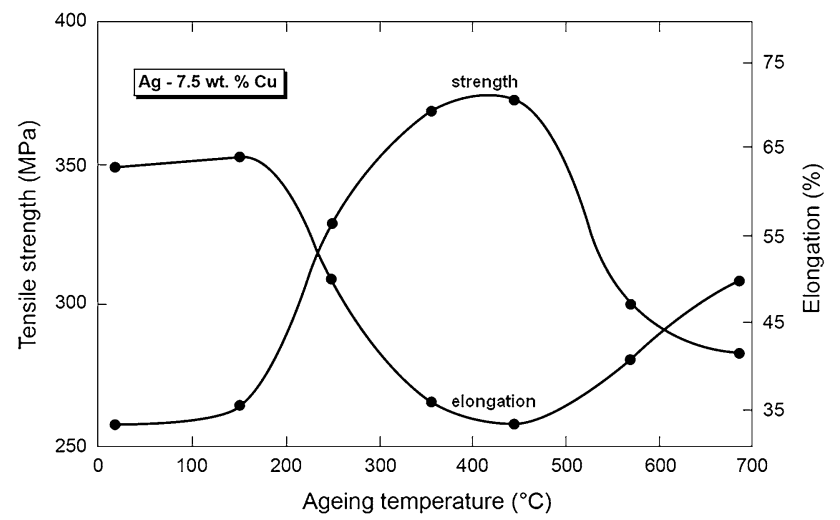

Fig. 9 Effect of 30 min aging on the ambient temperature mechanical properties of $720^{\circ} \mathrm{C}$ solutionized and quenched standard silver, $\mathrm{Ag}-7.5$ wt.\% $\mathrm{Cu}[8]$ are invariably brittle" [1]. However, Table 3 shows that the unembrittled Cauldron sample, which exhibited extensive discontinuous precipitation, contained 3.44 wt.\% copper. Hence, the causality between discontinuous precipitation, copper content (above $3 \mathrm{wt} . \%$ ), and embrittlement is less certain than stated by Smith.

This argument can be expanded. Figure 10 is a probability plot of copper content in ancient silver objects of at least $95 \%$ purity. This figure includes data for the Vase and three samples from the Cauldron, and data ranges for the Kantharos and Kaptorga. The copper contents of the Kantharos, Vase, and embrittled Cauldron samples, which did not contained discontinuous precipitation, were below 3 wt.\%. The Kaptorga samples, also not containing discontinuous precipitation, had copper contents above 3 wt. $\%$ and close to that of the unembrittled Cauldron sample containing discontinuous precipitation. Thus, there is no definitive relationship between discontinuous precipitation, copper content, and embrittlement.

\section{Discontinuous Precipitation of Copper and Authenticity}

The suggestion by Schweizer and Meyers [4, 5] that ancient silver artifacts could be authenticated by the characteristics of discontinuous precipitation concerns two aspects, the precipitate width and its detailed morphology. This suggestion can be evaluated using the reaction kinetics information in Fig. 3 and metallographic results for the Cauldron [23, 24].
Fig. 10 Probability plot of copper in ancient silver containing at least $95 \mathrm{wt} \%$ silver [23], with addition of the ranges in copper content for the Kantharos and Kaptorga, see Table 2

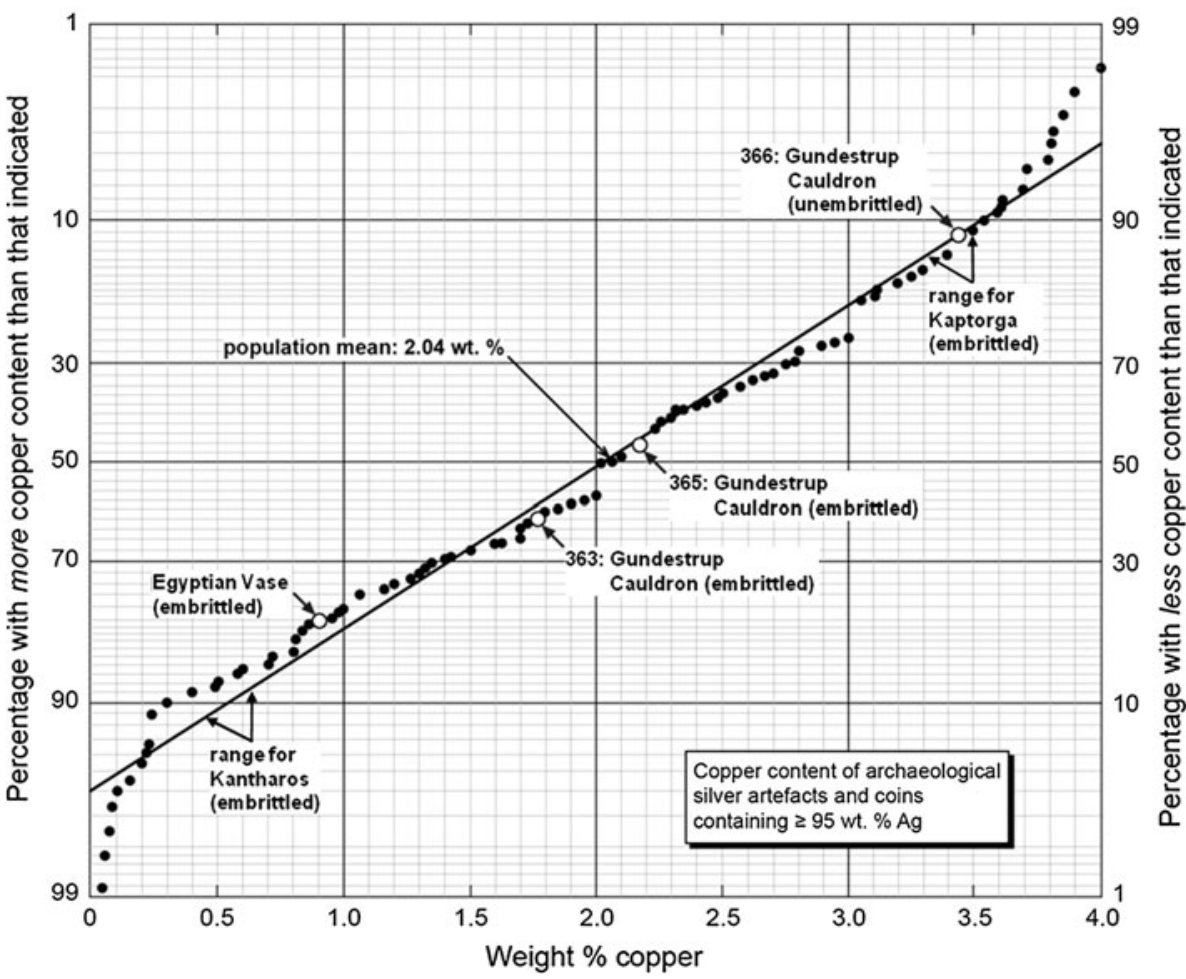


Figure 11 is a previously unpublished SEM metallograph from a series taken for the unembrittled annealed sample 366 from the Cauldron. There is extensive discontinuous precipitation along the grain boundaries, and the widths of the precipitates vary widely, from about $2 \mu \mathrm{m}$ to at least $20 \mu \mathrm{m}$. Furthermore, since the Cauldron is approximately 2000 years old, the extrapolations in Fig. 3 indicate that under ambient temperature conditions the maximum precipitate width should be about $2 \mu \mathrm{m}$, as mentioned previously. Clearly, the extrapolations are inapplicable and cannot be used for dating an ancient artifact, even if the precipitate widths would be uniform.

With respect to the detailed morphology of the precipitate, Schweizer and Meyers [4, 5] suggested that it might form regular lamellae, whose spacing would depend on the aging temperature such that one could distinguish between genuine long-term precipitation at ambient temperatures and short-term precipitation at elevated temperatures. However, Fig. 11 shows that the precipitate appears amorphous and finely mottled - there is no suggestion of a lamellar microstructure. This is consistent with many other results, including the samples examined by Schweizer and Meyers and the optical metallographs in Fig. 2.

Thus, like the precipitate widths, the precipitate microstructure cannot be used for dating an ancient artifact.

Nevertheless, the occurrence of discontinuous precipitation in a silver artifact may be regarded as additional evidence of antiquity, combined with information on provenance and stylistic features.

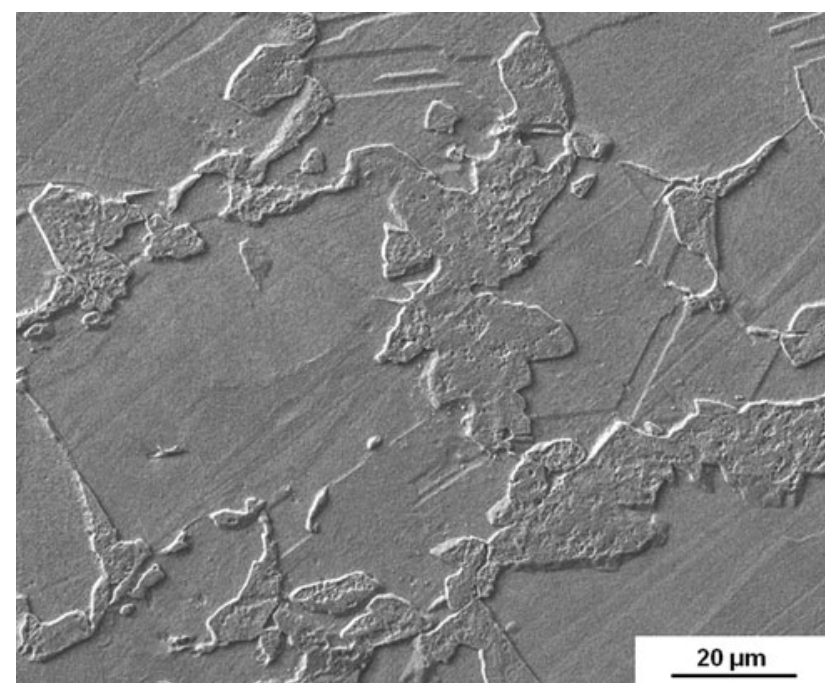

Fig. 11 SEM secondary electron (SE) metallograph of the unembrittled annealed sample 366 from the Gundestrup Cauldron, showing discontinuous precipitation of copper at the grain boundaries: sample etched with ammoniacal hydrogen peroxide

\section{Discussion}

These seven case studies have shown that discontinuous precipitation of copper in ancient silver is much less significant than was previously thought and suggested [1-5]. In particular, the proposed primary role of discontinuous precipitation in the embrittlement process $[1,2]$ is seen to be non-existent. At the most, this type of precipitation may facilitate the process of intergranular corrosion-induced embrittlement. This suggestion is made because the cracking process starts with intergranular corrosion pitting [30], which is most probably due to local strains at the grain boundaries, owing to dislocation pile-ups, and copper segregation to the boundaries. Copper segregation to the grain boundaries, either atomically or by precipitation, would make the grain boundaries anodic compared to the silver matrix, thereby facilitating electrochemical dissolution of the boundaries.

As mentioned earlier, two of the case studies, the Vase and Cauldron, have demonstrated the primary importance of retained cold-work in causing and facilitating corrosioninduced embrittlement $[23,24,26]$.

The primary role of retained cold-work is emphasized by the fact that it suppresses or inhibits discontinuous precipitation. This is concluded from the Cauldron samples: Only the unembrittled annealed sample 366 showed discontinuous precipitation, even though it had a lower copper content than the embrittled cold-worked sample 361, see Table 3. Furthermore, recent studies indicate that corrosion-induced embrittlement is a form of stress corrosion cracking (SCC) [29, 30]. In artifacts with retained cold-work, the residual stresses act in combination with the burial environment to cause mainly intergranular cracking, as in the embrittled Cauldron samples and the Head, see Tables 2 and 3. Higher amounts of retained cold-work increase the tendency for transgranular cracking, as in the Vase and sample 365 from the Cauldron. The argument for SCC has been extended to include annealed artifacts like the Kaptorga, which because of its hollow and thin-walled geometry would have experienced high externally applied stresses from the weight of the soil during burial [30].

\section{Conclusions}

(1) The significance of discontinuous precipitation of copper for the embrittlement of ancient silver is limited. Discontinuous precipitation may facilitate the process of intergranular corrosion-induced embrittlement, but is not the primary cause. Nor is it responsible for transgranular corrosion-induced embrittlement and microstructurally-induced embrittlement, which is most probably due to lead. 
(2) The characteristics of discontinuous precipitation cannot be used to determine the age and authenticity of silver artifacts. However, when combined with information on provenance and stylistic features, the occurrence of discontinuous precipitation in a silver artifact may be regarded as additional evidence of antiquity.

\section{References}

1. C.S. Smith, The interpretation of microstructures of metallic artifacts, in Application of Science in Examination of Works of Art, ed. by W.J. Young (Boston Museum of Fine Arts, Boston, 1965), pp. 20-52

2. A.E. Werner, Two problems in the conservation of antiquities: corroded lead and brittle silver, in Application of Science in Examination of Works of Art, ed. by W.J. Young (Boston Museum of Fine Arts, Boston, 1965), pp. 96-104

3. F. Schweizer, P. Meyers, Structural changes in ancient silver alloys: the discontinuous precipitation of copper. Paper 78/23/5, ICOM Committee for Conservation 5th Triennial Meeting, Zagreb (1978)

4. F. Schweizer, P. Meyers, Authenticity of ancient silver objects: a new approach. MASCA J. 1, 9-10 (1978)

5. F. Schweizer, P. Meyers, A new approach to the authenticity of ancient silver objects: the discontinuous precipitation of copper from a silver-copper alloy, in Proceedings of the 18th International Symposium on Archaeometry and Archaeological Prospection (Rheinland-Verlag GmbH, Cologne, 1979), pp. 287-298

6. W. Gust, Discontinuous precipitation in binary metallic systems, Phase Transformations, vol. II (The Institution of Metallurgists, London, 1979), pp. II-27-II-68

7. W. Fraenkel, Zur kenntnis der vorgänge bei der entmischung übersättigter mischkristalle. Z. Anorg. Allg. Chem. 154, 386-394 (1926)

8. A.L. Norbury, The effect of quenching and tempering on the mechanical properties of standard silver. J. Inst. Met. 39, 145$172(1928)$

9. N. Ageew, M. Hansen, G. Sachs, Entmischung und eigenschaftänderungen übersättigter silber-kupferlegierungen. Z. Phys. 66, 350-376 (1930)

10. C.S. Barrett, H.F. Kaiser, R.F. Mehl, Studies upon the Widmanstätten structure, VII-the copper-silver system. Trans. Am. Inst. Min. Metall. Eng. 117, 39-60 (1935)

11. M. Cohen, Aging phenomena in a silver-rich copper alloy. Trans. Am. Inst. Min. Metall. Eng. 124, 138-157 (1937)

12. F.W. Jones, P. Leech, C. Sykes, Precipitation in single crystals of silver-rich and copper-rich alloys of the silver-copper system. Proc. R. Soc. Lond. Ser. A 181, 154-168 (1942)

13. M.L.V. Gayler, W.E. Carrington, Metallographic study of the precipitation of copper from a silver-rich silver-copper alloy. J. Inst. Met. 73, 625-639 (1947)

14. R.G. Rose, The precipitation of copper from a silver-5.5\% copper solid solution at $220^{\circ} \mathrm{C}$. Acta Metall. 5, 404-405 (1957)

15. W. Leo, Elektronenmikroskopische untersuchungen zur ausscheidung in aushärtbaren silber-kupfer-legierungen. Z. Metallkunde 58, 456-461 (1967)
16. B. Predel, H. Ruge, Untersuchung der kinetik der diskontinuierlichen entmischung übersättigter silber-mischkristalle. Z. Metallkunde 59, 777-781 (1968)

17. W. Scharfenberger, G. Schmitt, H. Borchers, Über die kinetik der diskontinuierlichen ausscheidung der silberlegierung mit 7, 5 gew.-\%cu. Z. Metallkunde 63, 553-560 (1972)

18. W. Gust, B. Predel, K. Diekstall, Zur diskontinuierlichen ausscheidung in silber-6, 2 at.\%-kupfer-dreikristallen. Z. Metallkunde 69, 75-80 (1978)

19. A. Pawlowski, Discontinuous precipitation in deformed FCC solid solution. Scripta Metall. 13, 785-790 (1979)

20. A. Pawlowski, Changes of free energy in the process of discontinuous precipitation in deformed FCC solid solution. Scr. Metall. 13, 791-794 (1979)

21. D.B. Williams, J.W. Edington, The discontinuous precipitation reaction in dilute Al-Li alloys. Acta Metall. 24, 323-332 (1976)

22. R.D. Doherty, Diffusive phase transformations in the solid state, in Physical Metallurgy, vol. II, ed. by R.W. Cahn, P. Haasen (Elsevier, Amsterdam, 1996), pp. 1456-1458

23. R.J.H. Wanhill, Embrittlement of ancient silver. J. Fail. Anal. Prev. 5(1), 41-54 (2005)

24. R.J.H. Wanhill, T. Hattenberg, J.P. Northover, EBSD of corrosion, deformation and precipitation in the Gundestrup Cauldron, in Ligas metálicas: investigação e conservação, ed. by A.C. Ferreira de Silva, P.M. Homem (Faculdade de Letras da Universidade do Porto, Porto, 2008), pp. 46-61

25. K.C. Lefferts, Technical notes. Metrop. Mus. Art MMA Bull. 25(3), 147-151 (1966)

26. R.J.H. Wanhill, J.P.H.M. Steijaert, R. Leenheer, J.F.W. Koens, Damage assessment and preservation of an Egyptian silver vase (300-200 BC). Archaeometry 40, 123-137 (1998)

27. J. Děd, A. Šilhová, Corrosion damage of silver objects from archaeological findings, in Proceedings of Conservators and Restorers Conference Pilsen (Technical Museum of Brno, Brno, 2005), pp. 44-48 (in Czech)

28. J. Vaníčková, J. Děd, P. Bartuška, P. Lejček, Intergranular failure of Roman silver artefacts. Mater. Sci. Forum 567-568, 213-216 (2007)

29. R.J.H. Wanhill, Case histories of ancient silver embrittlement. J. Fail. Anal. Prev. 11(3), 178-185 (2011)

30. R.J.H. Wanhill, Stress corrosion cracking in ancient silver. Stud. Conserv. (in-press)

31. I.G. Ravich, Annealing of brittle archaeological silver: microstructural and technological study, in $10^{\text {th }}$ Triennial Meeting of the International Council of Museums Committee for Conservation, Preprints of the Seminar: August 22/27, 1993, II, pp. 792-795, Washington, DC (1993)

32. F.C. Thompson, A.K. Chatterjee, The age-embrittlement of silver coins. Stud. Conserv. 1, 115-126 (1954)

33. R.J.H. Wanhill, Archaeological silver embrittlement: a metallurgical inquiry. NLR Technical Publication NLR-TP-2002-224, National Aerospace Laboratory NLR, Amsterdam, the Netherlands (2002)

34. H. McKerrell, R.B.K. Stevenson, Some analyses of Anglo-Saxon and associated Oriental silver coinage, in Methods of Chemical and Metallurgical Investigation of Ancient Coinage, ed. by E.T. Hall, D.M. Metcalf (Royal Numismatic Society, London, 1972), pp. 195-209 